\title{
Nickel Iron Diselenide for Highly Efficient and Selective Electrocatalytic Conversion of Methanol to Formate
}

Junshan Li, ${ }^{\text {a }}$ Congcong Xing, ${ }^{\text {b,c }}$ Yu Zhang, ${ }^{\mathrm{b}}$ Maria Chiara Spadaro, ${ }^{\mathrm{d}}$ Ting Zhang, ${ }^{\mathrm{d}}$ Qianbao $\mathrm{Wu},{ }^{\mathrm{a}}$ Yunan Yi, ${ }^{\mathrm{a}}$ Shenlan He, ${ }^{\mathrm{a}}$ Jordi Llorca, ${ }^{\mathrm{c}}$ Jordi Arbiol, ${ }^{\mathrm{de}}$ Andreu Cabot, ${ }^{\mathrm{b}, \mathrm{e}} *$ Chunhua Cui ${ }^{\mathrm{a} *}$ a Molecular Electrochemistry Laboratory, Institute of Fundamental and Frontier Sciences, University of Electronic Science and Technology of China, 610054 Chengdu, P. R. China. b Catalonia Institute for Energy Research - IREC, Sant Adrià de Besòs, Barcelona, 08930, Spain.

c Institute of Energy Technologies, Department of Chemical Engineering and Barcelona Research Center in Multiscale Science and Engineering. Universitat Politècnica de Catalunya, EEBE, 08019 Barcelona, Spain.

d Catalan Institute of Nanoscience and Nanotechnology (ICN2), CSIC and BIST, Campus UAB, Bellaterra, 08193 Barcelona, Spain.

e ICREA, Pg. Lluís Companys 23, 08010 Barcelona, Spain.

\begin{abstract}
The electrooxidation of methanol to formate is an example of the potential use of renewable energies to add value to a biosourced chemical commodity. Additionally, methanol electrooxidation can replace the sluggish oxygen evolution reaction for hydrogen evolution or the electroreduction of other biomass-derived intermediates. Here, we demonstrate a noble metal-free catalyst, $\mathrm{Ni}_{1-\mathrm{x}} \mathrm{Fe}_{\mathrm{x}} \mathrm{Se}_{2}$, with a high potential for an efficient and selective methanol conversion to formate. At its optimum composition, $\mathrm{Ni}_{0.75} \mathrm{Fe}_{0.25} \mathrm{Se}_{2}$, this diselenide is able to produce $0.47 \mathrm{mmol} \mathrm{cm}^{-2} \mathrm{~h}^{-1}$ of formate at $50 \mathrm{~mA} \mathrm{~cm}^{-2}$ with a Faradaic conversion efficiency of $99 \%$. We further demonstrate that $\mathrm{Ni}_{1-\mathrm{x}} \mathrm{Fe}_{\mathrm{x}} \mathrm{Se}_{2}$-based catalysts are able to continuously work for over 50,000 s with a minimal loss of efficiency, delivering initial current densities above $50 \mathrm{~mA} \mathrm{~cm}^{-2}$ and $2.2 \mathrm{~A} \mathrm{mg}^{-1}$ in a $1.0 \mathrm{M} \mathrm{KOH}$ electrolyte with $1.0 \mathrm{M}$ methanol at $1.5 \mathrm{~V}$ vs. RHE.
\end{abstract}

Keywords: electrocatalysis; methanol oxidation reaction; selenide; nanoparticle; formic acid; biorefinery; biomethanol; formate 


\section{Introduction}

Electrochemistry can play an important role in future biorefineries by allowing the valorization of biomass-derived chemicals using renewable energies such as wind and solar. It is becoming evident that the electrocatalytic reforming of biomass-derived chemicals is a potential cost effective, $\mathrm{CO}_{2}$-neutral and clean approach to produce hydrogen, biofuels, and value-added chemicals, and it can be even a convenient approach to store renewable energy in chemical bonds.[1-3]

Methanol is the most used commodity chemical. It can be obtained from $\mathrm{CO}_{2}$ and different forms of biomass, including municipal, agricultural and forest waste. Methanol is used as a fuel in direct methanol fuel cells, but also as precursor or building block for the synthesis of other chemicals.[4] Currently, close to one million tons of formic acid are produced every year from the combination of methanol with $\mathrm{CO}$ at high pressure and the hydrolysis of the resulting methyl formate.[5] This is a cost-effective process because the price per metric ton of formate is a fourfold higher than that of methanol.[6,7] Formate is an essential and highly versatile chemical in many sectors, including chemical, textile, rubber, leather, pharmaceutic and printing industries. Formic acid can be also used as a fuel in direct formic acid fuel cells and for hydrogen storage.[8-11]

Among the possible alternative strategies to produce formate, the electrooxidation of (bio)methanol has several advantages, including a high energy efficiency, a potential high selectivity, the use of ambient pressures and temperatures, the potential use of electricity from renewable energy sources, its rapid activation and deactivation that allows using surplus energy when it becomes available, the scalability of the process, and its potential coupling with elecroreduction reactions to generate hydrogen or other valuable fuels or chemicals.[1014] The methanol oxidation reaction (MOR) to formate could be even coupled to the oxygen reduction reaction to cogenerate electricity.[15]

As a drawback, the electrochemical oxidation of methanol generally relies on noble metal-based and thus high cost electrocatalysts, which limits application at an industrial scale.[16,17] Recently, a great deal of effort has been devoted to the development of $\mathrm{Ni}$ - and 
Co-based catalysts for the MOR.[18] Ni-based catalysts are characterized by particularly outstanding performances in alkaline media. This high performance is correlated with the surface oxidation of $\mathrm{Ni}$ to $\mathrm{NiOOH}$, which is considered the MOR active phase.[19-25] Using in-situ infrared spectroscopy together with nuclear magnetic resonance spectroscopy, we recently demonstrated a $100 \%$ electrochemical conversion of methanol to formate on branched $\mathrm{Ni}_{3} \mathrm{C}$ particles.[26] Other groups have demonstrated the combination of $\mathrm{Fe}$ and $\mathrm{Ni}$ to allow efficient MOR with current densities up to $1.71 \mathrm{~A} \mathrm{mg}^{-1}$ at $1.58 \mathrm{~V}$ vs. RHE, well above the values obtained for elemental $\mathrm{Ni}$ and Fe catalyst.[27] Besides, nickel selenide nanowires grown on nickel foil were demonstrated to deliver much higher current densities than the respective metal, oxide and sulfide, while at the same time showing an excellent stability.[28]

We take advantage of recent advances in the field to develop a higher performance catalyst for the cost effective methanol oxidation to formate. We present here an electrocatalysts based on bimetallic nickel-iron diselenide nanorods produced at low temperature in solution. The $\mathrm{Ni} / \mathrm{Fe}$ ratio within the nanorods is tuned through the full $\mathrm{Ni} / \mathrm{Fe}$ range to determine the optimum composition. The performance of these materials toward the electrocatalytic oxidation of methanol to formate is analyzed and its activity, selectivity and stability is determined. 


\section{Experimental Section}

Chemicals. Nickel (II) acetylacetonate (Ni(acac) 2, 96\%), iron (III) acetylacetonate (Fe(acac) $)_{3},>99 \%$ ), selenium powder (Se, 200 mesh 99.5\%), and oleylemine (OAm, $\mathrm{C}_{18} \mathrm{H}_{37} \mathrm{~N}$, 80-90\%) were purchased from Acros Organics. Potassium carbonate $\left(\mathrm{K}_{2} \mathrm{CO}_{3}, 99.5 \%\right)$, potassium bicarbonate $\left(\mathrm{KHCO}_{3}, 99.7 \%\right)$, 1,2-ethanedithiol (EDT, $\mathrm{HSCH}_{2} \mathrm{CH}_{2} \mathrm{SH},>98 \%$ ), potassium hydroxide $(\mathrm{KOH}, 85 \%)$, oleic acid $\left(\mathrm{OAc}, \mathrm{C}_{18} \mathrm{H}_{34} \mathrm{O}_{2}, 99 \%\right)$, carbon black $(\mathrm{CB}$, Vulcan XC72), and Nafion (10 wt.\%, perfluorinated ion-exchange resin, dispersion in water) were purchased from sigma Aldrich. Analytical grade hexane and ethanol were obtained from various sources. MilliQ water $(18.2 \mathrm{M} \Omega \cdot \mathrm{cm})$ was used for ink preparation and IC measurements. All chemicals were used as received, without any purification.

$\mathbf{N i}_{1-\mathbf{x}} \mathrm{Fe}_{\mathbf{x}} \mathrm{Se}_{2}$ precursor. To prepare the precursor required to produce $0.2 \mathrm{~g}$ of $\mathrm{Ni}_{1-\mathrm{x}} \mathrm{Fe}_{\mathrm{x}} \mathrm{Se}_{2} \mathrm{NRs}$, (1-x) of $\mathrm{mM} \mathrm{Ni}(\mathrm{acac})_{2}, \mathrm{x} \mathrm{mM}$ of $\mathrm{Fe}(\mathrm{acac})_{3}$, and $2 \mathrm{mM}$ of Se powder were placed within a glass vial. Then $5 \mathrm{~mL}$ of $\mathrm{OAm}$ and $0.5 \mathrm{~mL}$ of EDT were added while stirring. Upon EDT incorporation, the color of the solution immediately turned from transparent to light yellow. The mixture was stirred for $2 \mathrm{~h}$ at $50{ }^{\circ} \mathrm{C}$. The obtained precursor was then filtered through a $0.2 \mu \mathrm{m}$ filter before using. All the processes were carried out inside an argon-filled glove box.

$\mathbf{N i}_{1-\mathbf{x}} \mathbf{F e}_{\mathbf{x}} \mathbf{S e}_{2}$ NRs. $20 \mathrm{ml}$ of OAm was placed in a $50 \mathrm{ml}$ three-neck flask and kept under vacuum first at room temperature for $20 \mathrm{~min}$ and then at $80{ }^{\circ} \mathrm{C}$ for $30 \mathrm{~min}$ to obtain a clear solution and remove low boiling point impurities. Afterward, the solvent was heated to $220^{\circ} \mathrm{C}$ under $\mathrm{Ar}$, and at this point the $\mathrm{Ni}_{1-\mathrm{x}} \mathrm{Fe}_{\mathrm{x}} \mathrm{Se}_{2}$ precursor solution was injected into the flask. Upon injection, temperature dropped to $\sim 210^{\circ} \mathrm{C}$. The mixture was allowed to recover the $220^{\circ} \mathrm{C}$ and maintained at this temperature for $10 \mathrm{~min}$. Afterward, the solution was rapidly cooled, $\sim 80$ ${ }^{\circ} \mathrm{C} / \mathrm{min}$, to room temperature using a water bath. During cooling, when the flask reached $\sim 70$ ${ }^{\circ} \mathrm{C}, 2 \mathrm{ml}$ of OAc were added to replace the weakly bound OAm molecules. At ambient temperature, the crude solution was mixed with $10 \mathrm{ml}$ of hexane and the product was isolated by centrifugation at $8000 \mathrm{rpm}$ for $5 \mathrm{~min}$. Particles were then dispersed again in hexane and precipitated one more time by centrifugation in the presence of ethanol. The NPs were finally re-dispersed in hexane and kept in the glovebox until their posterior use. 
Material characterization: The crystal structure of the materials was characterized by X-ray diffraction (XRD) using a Bruker AXS D8 Advance $(\mathrm{Cu} \mathrm{K}$ radiation: $\lambda=1.5106 \AA)$. Refinement of the laboratory diffraction patterns were obtained by the Rietveld method with the GSAS-II package. Scanning electron microscopy (SEM) measurements were performed on a Gemini 300 field emission scanning electron microscope (ZEISS, Germany) equipped with an AZtecOne UltimMax40 energy spectrometer. High-resolution transition electron macroscopy (HRTEM) together with scanning TEM (STEM) investigation was performed on a field emission gun FEI Tecnai F20 microscope. High angle annular dark-field (HAADF) STEM was combined with electron energy loss spectroscopy (EELS) in the Tecnai microscope by using a GATAN QUANTUM filter. X-ray photoelectron spectroscopy (XPS) analyses were conducted on a SPECS system. Fourier transform infrared spectroscopy (FTIR) analysis were performed on an Alpha Bruker FTIR spectrometer with a platinum attenuated total reflectance (ATR) single reflection module. Electron paramagnetic resonance (EPR) spectroscopy was conducted on a Bruker EMXplus instrument (Bruker, Germany) with a microwave frequency of $9.40 \mathrm{GHz}$ at $100 \mathrm{~K}$. Around $10 \mathrm{mg}$ of sample was loaded in a quartz EPR tube for each EPR measurement.

Electrochemical characterization. Electrochemical performance was measured on a Bio-logic SP-200 potentiostat at room temperature. All measurements were carried out using a conventional three-electrode system: a Pt wire as counter electrode (CE), a $5 \mathrm{~mm}$ diameter glassy carbon as working electrode (WE) and an $\mathrm{Ag} / \mathrm{AgCl}$ as reference electrode (RE). To prepare the WE, $5 \mathrm{mg}$ NRs and $10 \mathrm{mg} \mathrm{CB}$ were dispersed in $3 \mathrm{ml}$ of MilliQ water/ethanol $(\mathrm{v} / \mathrm{v}=1: 1)$ and $100 \mu \mathrm{L}$ of a $10 \mathrm{wt} \%$ Nafion. After vigorously sonicating for 1 hour, $3 \mu \mathrm{L}$ of the prepared ink was drop-casted on a carefully cleaned glassy carbon (GC) electrode, and then dried naturally in open air. The prepared alkaline electrolyte was bubbled with high-purity $\mathrm{N}_{2}$ gas for half an hour before exploring the electrocatalytic performance. Cyclic voltammetry $(\mathrm{CV})$, chronoamperometry $(\mathrm{CA})$, and chronopotentiometry $(\mathrm{CP})$ techniques were applied to study the activity and stability of the electrocatalyst. The measured potential (E) vs. reversible hydrogen electrode (RHE) was obtained using the following equation:

$$
E_{v s . R H E}=E_{A g / A g C l}+E_{A g / A g C l}^{0}+0.059 \times p H
$$


where $\boldsymbol{E}_{\boldsymbol{A} \boldsymbol{g} / \boldsymbol{A} \boldsymbol{g} \boldsymbol{C l}}$ is the measured potential E vs. RHE, $\boldsymbol{E}_{\boldsymbol{A} \boldsymbol{g} / \boldsymbol{A g} \boldsymbol{C l}}$ is the potential of the RE vs. RHE (0.21 V according to the manufacturer's web site), and $\mathrm{pH}$ is the theoretical value of 1.0 $\mathrm{M} \mathrm{KOH.}$

Product quantification. The product of the methanol electrochemical oxidation was characterized by ion chromatography (IC, analysis lab). A freshly prepared $4.5 \mathrm{mM} \mathrm{KCO}$ and $0.8 \mathrm{mM} \mathrm{KHCO}_{3}$ solution was used as leachate solution. During the $\mathrm{CP}$ measurement at a constant current output, $0.5 \mathrm{~mL}$ solution was collected at the same time intervals and diluted into MilliQ water with a ratio of 1:19 for the IC measurement. The produced amount of the product was calibrated based on standard solution with known concentrations. Then, the Faradaic efficiency (FE) was calculated using the following equation:

$$
F E(\%)=\frac{\text { mol of product } \times n \times F}{\text { total charge passed }} \times 100 \%
$$

where $\mathrm{n}$ is the electron transfer number and $\mathrm{F}$ is the Faradaic constant $\left(96485 \mathrm{C} \mathrm{mol}^{-1}\right)$. 


\section{Results and discussion}

Nickel iron diselenide, $\mathrm{Ni}_{1-\mathrm{x}} \mathrm{Fe}_{\mathrm{x}} \mathrm{Se}_{2}$, particles were produced over their entire compositional range via a two-step solution-based approach. The process involved the dissolution of $\mathrm{Ni}$ and Fe acetylacetonates and Se powder in an EDT solution, and the subsequent reaction of the mixture in OAm at $220{ }^{\circ} \mathrm{C}$ (see scheme in Figure 1a and experimental section for details). The reaction product consisted of particles with elongated morphology, with an average width of ca. $10 \mathrm{~nm}$ and an average length of ca. $50 \mathrm{~nm}$ (Figures $1 \mathrm{~b}$ and $\mathrm{S} 1$ ). The Ni/Fe ratio was tuned by varying composition of the initial precursor solution (Table 1). Because the measured composition was in good agreement with the nominal composition, in the following we use the later to refer to the different samples.

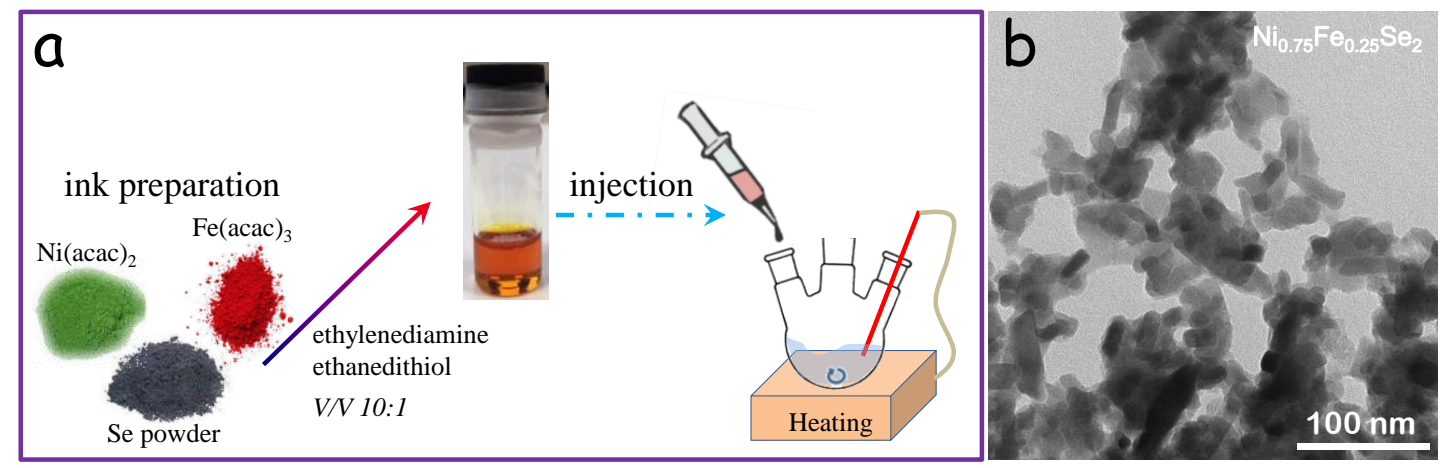

Figure 1. (a) Scheme of the solution-based approach used to prepare $\mathrm{Ni}_{1-\mathrm{x}} \mathrm{Fe}_{\mathrm{x}} \mathrm{Se}_{2}$. (b) Representative TEM macrograph of $\mathrm{Ni}_{0.75} \mathrm{Fe}_{0.25} \mathrm{Se}_{2}$ nanoparticles with elongated geometry.

XRD patterns obtained from $\mathrm{NiSe}_{2}$ and $\mathrm{FeSe}_{2}$ particles were properly indexed considering the cubic pa-3 and orthorhombic pnnm crystal structure, respectively (Figure $2 \mathrm{a}$ ). $\mathrm{Ni}_{0.75} \mathrm{Fe}_{0.25} \mathrm{Se}_{2}$ was found to crystalize in the cubic $\mathrm{NiSe}_{2}$ phase. Rietveld refinement of the XRD pattern of this sample showed a unit cell with $\mathrm{a}=\mathrm{b}=\mathrm{c}$ of $5.9449 \AA$, slightly above the $5.9195 \AA$ measured for $\mathrm{NiSe}_{2}$ (Figure S2). When adding larger amounts of Fe, XRD peaks in the two-theta region of $28^{\circ}-38^{\circ}$ and $48^{\circ}-56^{\circ}$ became visible, evidencing the change from the cubic $\mathrm{NiSe}_{2}$ to the orthorhombic $\mathrm{FeSe}_{2}$ phase.

Table 1. Nominal and EDS Ni/Fe/Se atomic ratio of the $\mathrm{Ni}_{1-\mathrm{x}} \mathrm{Fe}_{\mathrm{x}} \mathrm{Se}_{2} \mathrm{NRs}$.

\begin{tabular}{|c|c|c|c|c|}
\hline \multirow{2}{*}{$\begin{array}{c}\mathrm{Ni}_{1-\mathrm{x}} \mathrm{Fe}_{\mathrm{x}} \mathrm{Se}_{2} \\
\text { (x) }\end{array}$} & \multicolumn{3}{|c|}{ Atomic ratio by EDS (\%) } & \multirow{2}{*}{$\begin{array}{l}\mathrm{Fe}^{*} \\
(\mathrm{x})\end{array}$} \\
\hline & $\mathrm{Ni}$ & $\mathrm{Fe}$ & $\mathrm{Se}$ & \\
\hline 0 & 33 & 0 & 67 & 0.00 \\
\hline 0.25 & 22 & 7 & 71 & 0.24 \\
\hline
\end{tabular}




\begin{tabular}{ccccc}
\hline 0.50 & 15 & 15 & 69 & 0.50 \\
0.75 & 9 & 23 & 68 & 0.72 \\
1.0 & 0 & 32 & 67 & 1.00 \\
\hline
\end{tabular}

* The atomic amount of $\mathrm{Fe}(\mathrm{x})$ was calculated by fixing the Se composition at 2 in $\mathrm{Ni}_{1-\mathrm{x}} \mathrm{Fe}_{\mathrm{x}} \mathrm{Se}_{2}$.

Figures $2 \mathrm{bc}$ and S3 display representative HRTEM micrographs and the indexed power spectra of $\mathrm{Ni}_{0.75} \mathrm{Fe}_{0.25} \mathrm{Se}_{2}$ and $\mathrm{Ni}_{0.50} \mathrm{Fe}_{0.50} \mathrm{Se}_{2}$ samples. In both cases, particles were imaged along their [010] zone axis. STEM-EELS chemical analyses showed $\mathrm{Fe}, \mathrm{Ni}$, and $\mathrm{Se}$ to be homogeneously distributed within the particles (Figure 2b). STEM-EELS quantitative analysis of the Ni and Fe content were in good agreement with SEM-EDS analysis, with the metal composition varying in the ranges $75-80 \%$ for $\mathrm{Ni}$ and $20-25 \%$ for $\mathrm{Fe}$ in $\mathrm{Ni}_{0.75} \mathrm{Fe}_{0.25} \mathrm{Se}_{2}$ (Figure 2b), and in the range $45-55 \%$ for both elements in $\mathrm{Ni}_{0.5} \mathrm{Fe}_{0.5} \mathrm{Se}_{2}$ (Figure S3a). HRTEM analysis confirmed the $\mathrm{Ni}_{1-\mathrm{x}} \mathrm{Fe}_{\mathrm{x}} \mathrm{Se}_{2}$ crystal structure to change symmetry when increasing the $\mathrm{Fe}$ amount, from cubic $\mathrm{NiSe}_{2}$ pa-3 with space group 205 to orthorhombic $\mathrm{FeSe}_{2}$ pnnm, space group 58, in good agreement with XRD analyses (Figure 2a). According to HRTEM analysis, $\mathrm{Ni}_{0.50} \mathrm{Fe}_{0.50} \mathrm{Se}_{2}$ already crystallized in the orthorhombic structure and its power spectrum could be simulated using orthorhombic $\mathrm{FeSe}_{2}$ with a $50 \%$ replacement of Fe by Ni (Figure S3b).

High resolution XPS spectra of the Ni $2 \mathrm{p}_{3 / 2}, \mathrm{Fe} 2 \mathrm{p}_{3 / 2}$ and $\mathrm{Se} 3 \mathrm{~d}$ regions of $\mathrm{Ni}_{0.75} \mathrm{Fe}_{0.25} \mathrm{Se}_{2}$ are displayed in Figures 2c and S4. Figure S5 displays XPS data obtained from $\mathrm{NiSe}_{2}$. The main contribution to the XPS spectra of the two metals provided from surface oxidized states, $\mathrm{NiO}_{\mathrm{x}}$ and $\mathrm{FeO}_{\mathrm{x}}$, although bands corresponding to $\mathrm{Ni}$ and $\mathrm{Fe}$ within a selenide environment where also clearly visible.[29] Surface oxidation took place during sample handling and transportation, as commonly observed in related materials.[30,31] The Se 3d spectra also showed two well defined contributions associated to an oxide component and to Se within a metal selenide environment.[32] The addition of a second minor oxidized component was required to properly fit the experimental data. These XPS spectra are in good agreement with data published in previous nickel iron selenides reports.[33-35] 

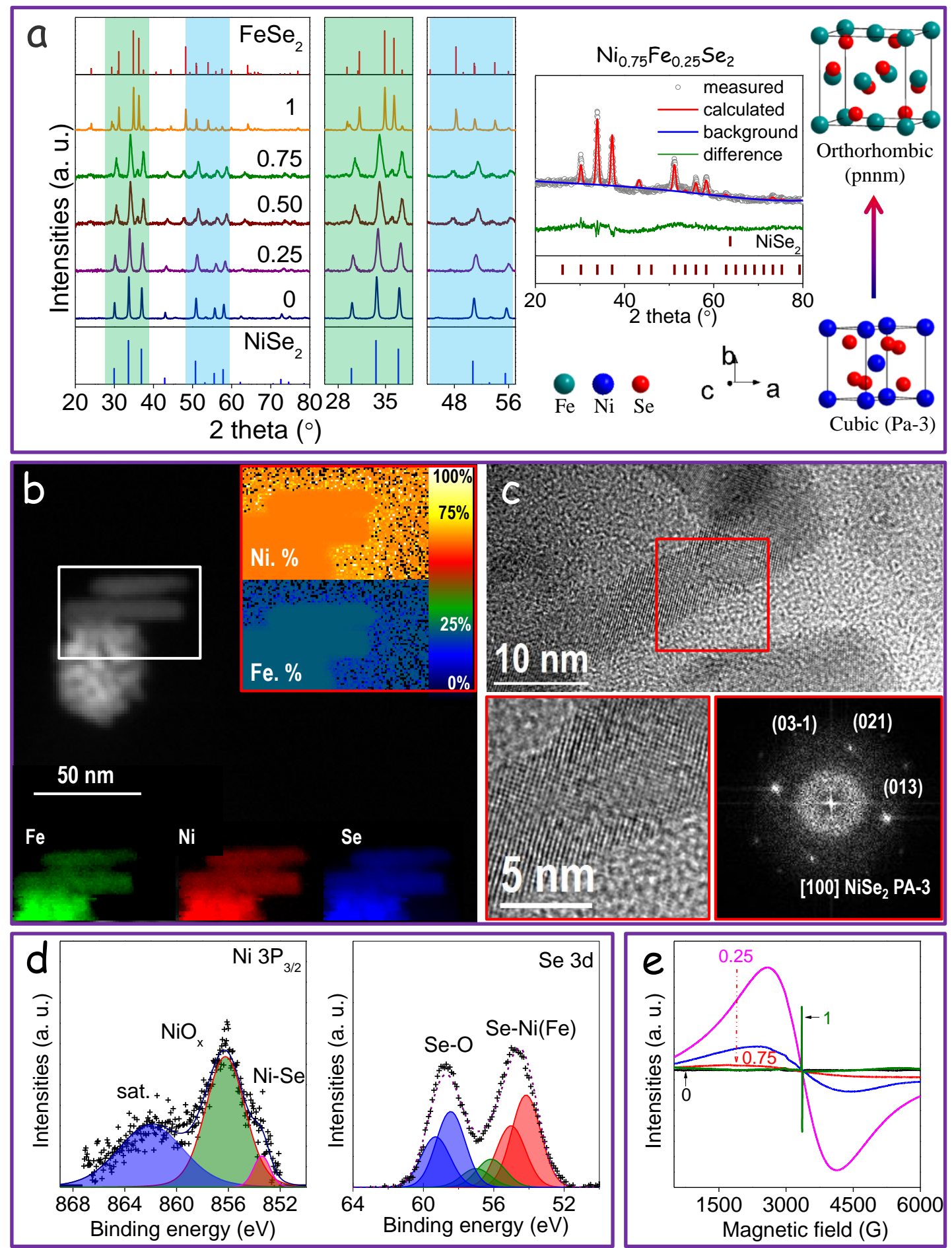

Figure 2. (a) XRD pattern of $\mathrm{Ni}_{1-\mathrm{x}} \mathrm{Fe}_{\mathrm{x}} \mathrm{Se}_{2}$, Rietveld refinement of the $\mathrm{Ni}_{0.75} \mathrm{Fe}_{0.25} \mathrm{Se}_{2}$ pattern $\left(\mathrm{GOF}=1.27 . \mathrm{R}_{\mathrm{w}}=9.44 \%\right)$ and scheme of the crystal structure of $\mathrm{NiSe}_{2}$ and $\mathrm{FeSe}_{2}$. (b) HAADF-STEM image and EELS-STEM maps for $\mathrm{Ni}_{0.75} \mathrm{Fe}_{0.25} \mathrm{Se}_{2}$. Maps were obtained using the Fe L-edges at $708 \mathrm{eV}$ (green), Ni L-edges at $855 \mathrm{eV}$ (red) and Se L edge at $1436 \mathrm{eV}$ (blue). Relative composition maps are also displayed. (c) HRTEM micrographs and indexed power spectra obtained from $\mathrm{Ni}_{0.75} \mathrm{Fe}_{0.25} \mathrm{Se}_{2}$ particles. (d) $\mathrm{Ni} 2 \mathrm{p}_{3 / 2}$, and $\mathrm{Se} 3 \mathrm{~d}$ high resolution XPS spectra from $\mathrm{Ni}_{0.75} \mathrm{Fe}_{0.25} \mathrm{Se}_{2}$. (e) EPR spectra of $\mathrm{Ni}_{1-\mathrm{x}} \mathrm{Fe}_{x} \mathrm{Se}_{2}$, labels indicate $\mathrm{x}$. 
EPR analysis was used to evidence the electronic interaction between $\mathrm{Ni}$ and $\mathrm{Fe}$ within $\mathrm{Ni}_{1-x} \mathrm{Fe}_{x} \mathrm{Se}_{2}$. Typically, $\mathrm{Fe}^{3+}, \mathrm{Ni}^{2+}$, and $\mathrm{Ni}^{0}$ have associated EPR signals, while $\mathrm{Fe}^{2+}, \mathrm{Fe}^{0}$, and $\mathrm{Ni}^{3+}$ do not.[36-38] As displayed in Figure 2e, no obvious resonance signal was detected from $\mathrm{NiSe}_{2}$ (black line). On the other hand, broad EPR signals were obtained for all the samples containing $\mathrm{Fe}$, with the highest signal intensity being observed for the sample containing the lowest amount of $\mathrm{Fe}: \mathrm{Ni}_{0.75} \mathrm{Fe}_{0.25} \mathrm{Se}_{2}$. The fluctuation of the signal intensity and position from sample to sample revealed the change of the metal valences as a function of the $\mathrm{Ni} / \mathrm{Fe}$ ratio and the existence of a strong interaction between the two metals.[38]

Prior to the electrocatalyst preparation, $\mathrm{Ni}_{1-\mathrm{x}} \mathrm{Fe}_{\mathrm{x}} \mathrm{Se}_{2}$ particles were precipitated and redispersed multiple times using ethanol and hexane. FTIR spectroscopy displayed the final particles to contain minimal amounts of organics on their surface (Figure S6). Electrocatalysts were prepared by mixing the cleaned $\mathrm{Ni}_{1-\mathrm{x}} \mathrm{Fe}_{x} \mathrm{Se}_{2}$ particles with $\mathrm{CB}$ and Nafion in DI water and ethanol (see experimental section for details).

The electrochemical performance of $\mathrm{Ni}_{1-\mathrm{x}} \mathrm{Fe}_{\mathrm{x}} \mathrm{Se}_{2}$-based electrodes was initially tested using a conventional three-electrode system in the potential window 1.0-1.7 V vs. RHE with a scan rate of $50 \mathrm{mV} \mathrm{s}^{-1}$ in an Ar-bubbled 1.0 M KOH electrolyte solution (Figure 3a). During the forward scan, a first current density peak for $\mathrm{NiSe}_{2}$ and $\mathrm{Ni}_{0.75} \mathrm{Fe}_{0.25} \mathrm{Se}_{2}$ electrodes at around $1.392 \mathrm{~V}$ was attributed to the transformation of $\mathrm{Ni}(\mathrm{OH})_{2}$ to $\mathrm{NiOOH}$.[39] At a potential higher than ca. $1.55 \mathrm{~V}$, a dramatic current rise associated to the production of oxygen was obtained. During the backward scan, the reduction peak at around $1.31 \mathrm{~V}$, both for $\mathrm{NiSe}_{2}$ and for $\mathrm{Ni}_{0.75} \mathrm{Fe}_{0.25} \mathrm{Se}_{2}$, was associated to the $\mathrm{Ni}$ reduction $\mathrm{Ni}^{3+} \rightarrow \mathrm{Ni}^{2+}$. Increasing the $\mathrm{Fe}$ composition, the redox peaks shifted positively and became less obviously, while no redox peaks were obtained with the $\mathrm{FeSe}_{2}$ electrodes below the OER potential. 

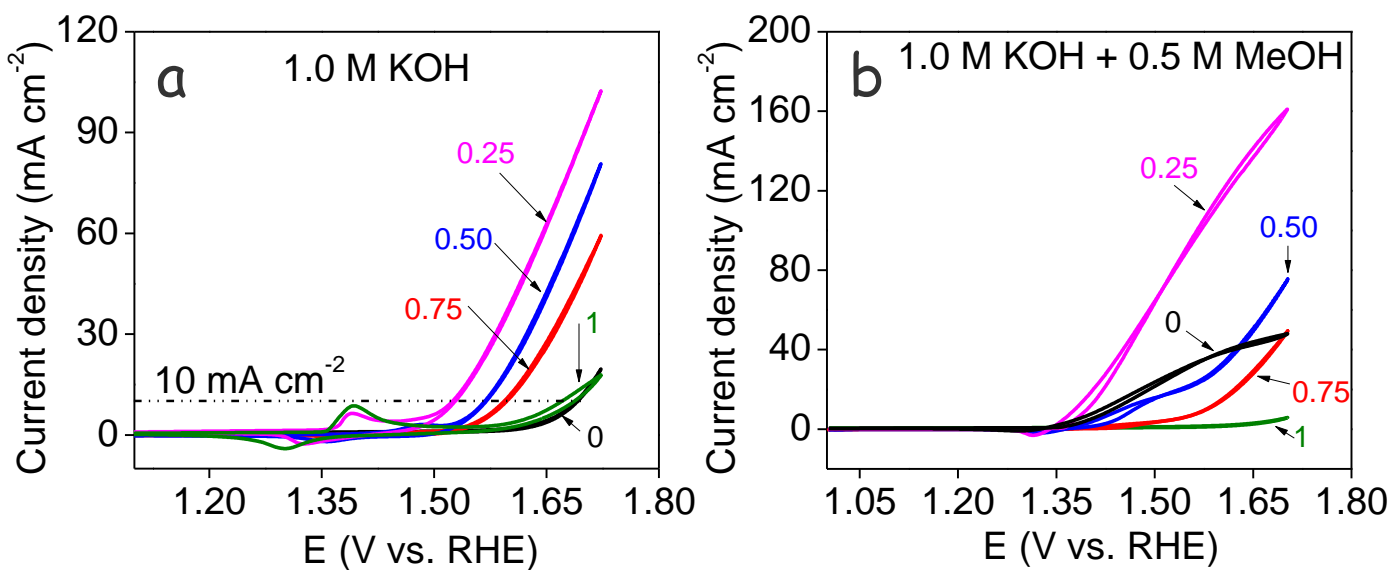

Figure 3. $\mathrm{CV}$ curves in $1.0 \mathrm{M} \mathrm{KOH}$ without (a) and in presence of $0.5 \mathrm{M}$ methanol (b) in the potential range $1.0-1.7 \mathrm{~V}$ vs. RHE and at a scan rate of $50 \mathrm{mV} \mathrm{s}^{-1}$.

When adding 0.5 $\mathrm{M}$ methanol in the alkaline media, a sharp rise in the current density for $\mathrm{NiSe}_{2}$ and $\mathrm{Ni}_{0.75} \mathrm{Fe}_{0.25} \mathrm{Se}_{2}$ electrodes was obtained at around $1.40 \mathrm{~V}$, i.e. after $\mathrm{NiOOH}$ formation (Figure 3b). On the other hand, a moderate increase of current density was obtained for the three electrodes containing larger amounts of Fe. Figure S7 displays the dependence of the MOR current density at $1.5 \mathrm{~V}$ on composition, after subtracting the current density delivered in $1.0 \mathrm{M} \mathrm{KOH}$. When increasing the Fe content, the current density increased from the $15.5 \mathrm{~mA}$ obtained for $\mathrm{NiSe}_{2}$ to the $57.6 \mathrm{~mA} \mathrm{~cm}{ }^{-2}$ for $\mathrm{Ni}_{0.75} \mathrm{Fe}_{0.25} \mathrm{Se}_{2}$ electrodes, to later decrease to 10.9, and $1.8 \mathrm{~mA} \mathrm{~cm}{ }^{-2}$ for $\mathrm{Ni}_{0.5} \mathrm{Fe}_{0.5} \mathrm{Se}_{2}$ and $\mathrm{Ni}_{0.25} \mathrm{Fe}_{0.25} \mathrm{Se}_{2}$ electrodes, respectively. $\mathrm{FeSe}_{2}$ electrodes delivered no MOR current.

Nyquist plots of the impedance response of a $\mathrm{Ni}_{0.75} \mathrm{Fe}_{0.25} \mathrm{Se}_{2}$ electrode measured at $1.6 \mathrm{~V}$ and $1.5 \mathrm{~V}$ in $1.0 \mathrm{M} \mathrm{KOH}$ with the presence and absence of $0.5 \mathrm{M}$ methanol are shown in Figure S8. At $1.6 \mathrm{~V}$, where oxygen was effectively generated, this electrode exhibited a smaller semicircle in the presence of methanol $\left(\mathrm{R}_{\mathrm{ct}}\right.$ of $\left.6.5 \Omega\right)$ than in its absence $\left(\mathrm{R}_{\mathrm{ct}}\right.$ of $\left.10.9 \Omega\right)$. As listed in Table $\mathrm{S} 1$, the fitting results at $1.5 \mathrm{~V}$ indicated a clearly enhanced charge-transfer process in the presence of $1.0 \mathrm{M}$ methanol with a $\mathrm{R}_{\mathrm{ct}}$ of only $5.4 \Omega$, much smaller than that in 1.0 $\mathrm{M} \mathrm{KOH}, 121.5 \Omega$. The improved impedance responses indicated that the electrooxidation of methanol was favored over the production of oxygen at the same potential. 

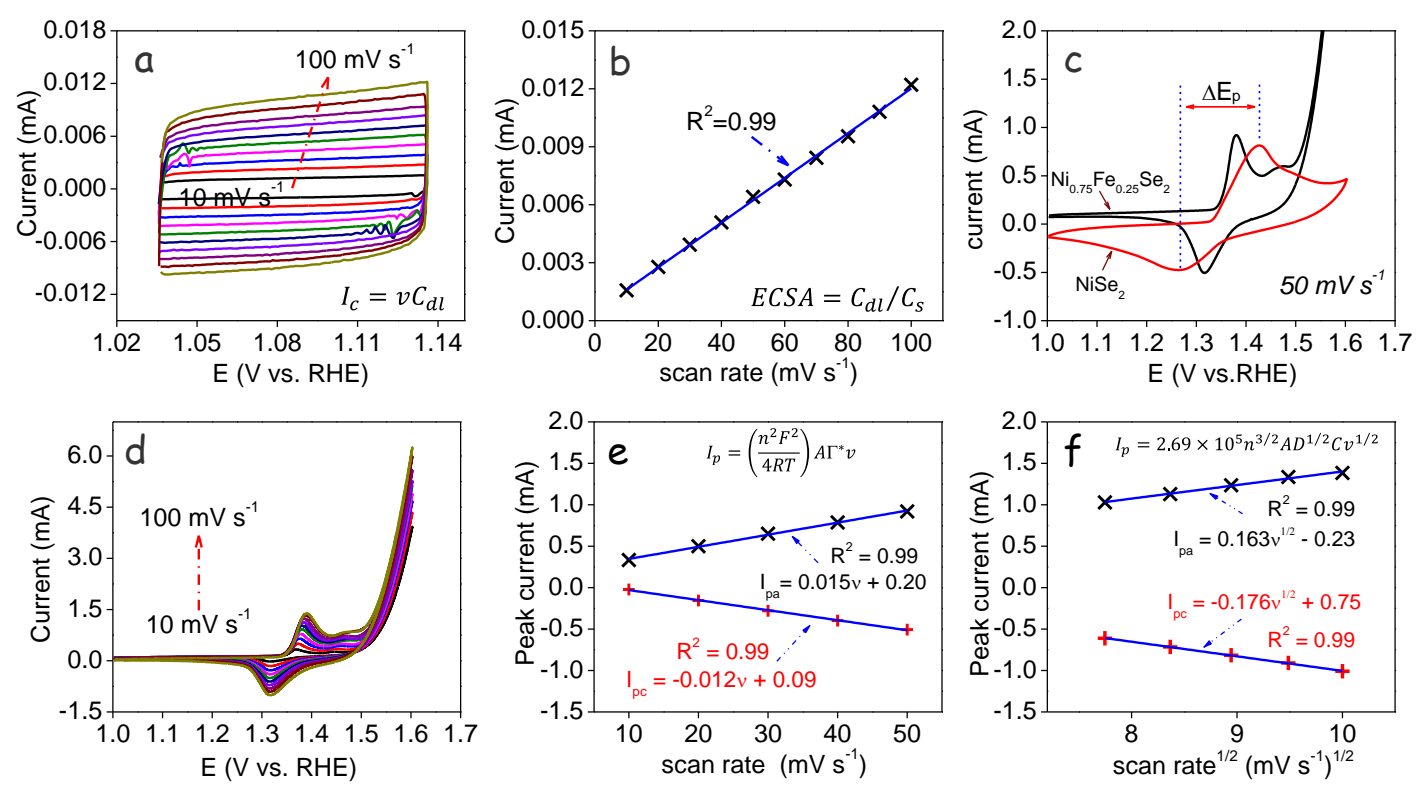

Figure 4. Electrochemical kinetics of a $\mathrm{Ni}_{0.75} \mathrm{Fe}_{0.25} \mathrm{Se}_{2}$-based electrode in $1.0 \mathrm{M} \mathrm{KOH}$. (a) CV curves in $1.0 \mathrm{M} \mathrm{KOH}$ in the non-faradaic potential range with a scan rate of $10-100 \mathrm{mV} \mathrm{s}^{-1}$. (b) Linear fitting of the current as a function of scan rate. (c) $\mathrm{CV}$ curves in the potential range from $1.0 \mathrm{~V}$ to $1.60 \mathrm{~V}$ at a scan rate of $50 \mathrm{mV} \mathrm{s}^{-1}$. The curve obtained from a $\mathrm{NiSe}_{2}$-based electrode is also plotted as reference. (d) CV curves in the potential range from $1.0 \mathrm{~V}$ to 1.60 $\mathrm{V}$ with variable scan rate of $10-100 \mathrm{mV} \mathrm{s}^{-1}$. (e) Linear fitting of the peak current as a function of the scan rate in the scan rate range from 10 to $50 \mathrm{mV} \mathrm{s}^{-1}$. (f) Linear fitting of the peak current as a function of the square root of scan rate in the scan rate range from 60 to 100 $\mathrm{mV} \mathrm{s}^{-1}$.

The electrochemically active surface area (ECSA) of the catalysts was determined using the double-layer capacitance $\left(\mathrm{C}_{\mathrm{dl}}\right)$ on the basis of $\mathrm{CVs}$ measured at a series of variable scan rates in the non-faradaic potential range.[40] Generally, $\mathrm{C}_{\mathrm{dl}}$ can be calculated from the linear fit of the current $(i)$ with the scan rate $(v)$ :

$$
i_{c}=v C_{d l}
$$

Then ECSA can be determined by dividing $\mathrm{C}_{\mathrm{dl}}$ by the specific capacitance:

$$
E C S A=C_{d l} / C_{S}
$$

where $\mathrm{C}_{\mathrm{s}}$ is $0.04 \mathrm{mF} \mathrm{cm}^{-2}$ based on values reported for metal electrodes in aqueous alkaline solution.[41]

$\mathrm{Ni}_{0.75} \mathrm{Fe}_{0.25} \mathrm{Se}_{2}$ electrodes displayed the largest ECSA values among the series tested, 62.5 $\mathrm{cm}^{2} \mathrm{~g}^{-1}$, threefold above the value obtained for $\mathrm{NiSe}_{2}$ electrodes, $18.75 \mathrm{~cm}^{2} \mathrm{~g}^{-1}$ (Figure S9). These values were below those reported for branched $\mathrm{Ni}_{3} \mathrm{C}$ particles, $108.6 \mathrm{~cm}^{2} \mathrm{~g}^{-1},[26]$ and 
$\mathrm{Ni}_{97} \mathrm{Bi}_{3}$ aerogels, $176.6 \mathrm{~cm}^{2} \mathrm{~g}^{-1}$, [42] but well above those of branched $\mathrm{Ni}_{0.75} \mathrm{Cu}_{0.25}, 0.12$ $\mathrm{cm}^{2} \mathrm{~g}^{-1}$, [43] and $\mathrm{NiO}$ nanotubes, $36.25 \mathrm{~m}^{2} \mathrm{~g}^{-1}$. [44]

In the faradaic region, the potential difference between the $\mathrm{Ni}(\mathrm{OH})_{2} \leftrightarrow \mathrm{NiOOH}$ redox peaks $\left(\Delta E_{p}\right)$ is related to the electron transfer kinetics between the electrode surface and the active centers.[45] As shown in Figure $4 c, \mathrm{Ni}_{0.75} \mathrm{Fe}_{0.25} \mathrm{Se}_{2}$ electrodes displayed the lowest $\Delta E_{p}, 65$ $\mathrm{mV}$ compared with the $91 \mathrm{mV}$ obtained for $\mathrm{NiSe}_{2}$, demonstrating the addition of $\mathrm{Fe}$ within the $\mathrm{NiSe}_{2}$ lattice to improve the reaction kinetics.

Figure $4 \mathrm{~d}$ displays $\mathrm{CV}$ curves at different scan rates in the range $10-100 \mathrm{mV} \mathrm{s}^{-1}$ for a $\mathrm{Ni}_{0.75} \mathrm{Fe}_{0.25} \mathrm{Se}_{2}$ electrode. While the peak current increased with the scan rate, the anodic peak potential shifted positively and the cathodic negatively. Qualitatively similar changes in the peak current and potential were observed for $\mathrm{NiSe}_{2}$ electrodes (Figure S10a). The shift of the peak potential is attributed to an electrochemical polarization and the limited reaction kinetics that control the formation of $\mathrm{NiOOH}$ species.[45]

The electrochemical performance of Ni-based electrodes is generally improved with the surface coverage of $\mathrm{Ni}(\mathrm{OH})_{2} / \mathrm{NiOOH}$ redox species $\left(\Gamma^{*}\right)$.[46] From the linear fit of the anodic and cathodic peak current $\left(\mathrm{I}_{\mathrm{p}}\right)$ with the sweep rate $(v)$ from 10 to $50 \mathrm{mV} \mathrm{s}^{-1}$ in the potential range of 1.0-1.6 $\mathrm{V}$, the surface coverage of redox species $\left(\Gamma^{*}\right)$ was estimated using the following equation:

$$
I_{p}=\left(\frac{n^{2} F^{2}}{4 R T}\right) A \Gamma^{*} v
$$

where $\mathrm{n}$ is the number of transferred electrons (assumed to be 1), $\mathrm{F}$ is the Faraday constant $\left(96,845 \mathrm{C} \mathrm{mol}^{-1}\right), \mathrm{R}$ is the gas constant $\left(8.314 \mathrm{~J} \mathrm{~K}^{-1} \mathrm{~mol}^{-1}\right), \mathrm{T}$ is absolute temperature $(295 \mathrm{~K})$ and $\mathrm{A}$ is the geometric surface area of the GC electrode $\left(0.196 \mathrm{~cm}^{2}\right)$.

Averaging the results obtained from the forward and reverse scans, $\Gamma^{*}$ of $\mathrm{Ni}_{0.75} \mathrm{Fe}_{0.25} \mathrm{Se}_{2}$ electrodes was $7.3 \times 10^{-8} \mathrm{~mol} \mathrm{~cm}^{-2}$ (Figure 4e), slightly larger than $\Gamma^{*}$ obtained for $\mathrm{NiSe}_{2}, 5.7$ $\times 10^{-8} \mathrm{~mol} \mathrm{~cm}^{-2}$ (Figure S10b). These values of $\Gamma^{*}$ were in agreement with those reported previously for $\mathrm{NiCo}_{2} \mathrm{Sn}_{2}\left(4.1 \times 10^{-8} \mathrm{~mol} \mathrm{~cm}^{-2}\right)$, [47] $\mathrm{Ni}_{97} \mathrm{Bi}_{3}\left(5.6 \times 10^{-7} \mathrm{~mol} \mathrm{~cm}{ }^{-2}\right)$, [42] Ni-C-30 $\left(8.9 \times 10^{-8} \mathrm{~mol} \mathrm{~cm}^{-2}\right),[48]$ and Ni nanoparticles $\left(1.9 \times 10^{-7} \mathrm{~mol} \mathrm{~cm}^{-2}\right) .[49]$ 
We further investigated the electrochemical activities based on the proton diffusivity (D) within the electrodes according to the Randles-Sevcik equation.[50] For Ni-based electrodes, the proton diffusion is generally regarded as a rate-limiting step that controls the $\mathrm{Ni}(\mathrm{OH})_{2} \leftrightarrow \mathrm{NiOOH}$ redox reaction.[51] In the scan rate range $60-100 \mathrm{mV} \mathrm{s}^{-1}$ (Figure 4f), the anodic and cathodic peak current $\left(I_{p}\right)$ was found to be a linear function of the square root of scan rate $\left(v^{1 / 2}\right)$, inferring a diffusion-limited redox reaction. Thus, the diffusion coefficient (D) could be determined from the following equation:

$$
I_{p}=2.69 \times 10^{5} n^{3 / 2} A D^{1 / 2} C v^{1 / 2}
$$

where $\mathrm{n}$ and $\mathrm{C}$ are the electron transfer number (assumed to be 1) and the initial concentration of redox species, respectively. Using this equation, the proton diffusion coefficient for the $\mathrm{Ni}_{0.75} \mathrm{Fe}_{0.25} \mathrm{Se}_{2}$ electrode was estimated at $2.2 \times 10^{-10} \mathrm{~cm}^{2} \mathrm{~s}^{-1}$, an order of magnitude above that of the $\mathrm{NiSe}_{2}$ electrode, $5.7 \times 10^{-11} \mathrm{~cm}^{2} \mathrm{~s}^{-1}$ (Figure S10c), which pointed at a much faster diffusion of the redox limiting specie in the sample containing Fe. The diffusion coefficient calculated for $\mathrm{Ni}_{0.75} \mathrm{Fe}_{0.25} \mathrm{Se}_{2}$ was in the same order of magnitude as that of branched $\mathrm{Ni}_{3} \mathrm{C}$ particles $\left(6.0 \times 10^{-9} \mathrm{~cm}^{2} \mathrm{~s}^{-1}\right)$, [26] branched $\mathrm{Ni}_{0.75} \mathrm{Cu}_{0.25}\left(2.9 \times 10^{-8} \mathrm{~cm}^{2} \mathrm{~s}^{-1}\right)$,[43] $\mathrm{Ni}-\mathrm{B}$ nanoparticles on nanoporous $\mathrm{Cu}$ electrode $\left(4.8 \times 10^{-9} \mathrm{~cm}^{2} \mathrm{~s}^{-1}\right)$,[52] and nanoporous Ni-Cu-P alloys $\left(3.65 \times 10^{-10} \mathrm{~cm}^{2} \mathrm{~s}^{-1}\right)$.[53]
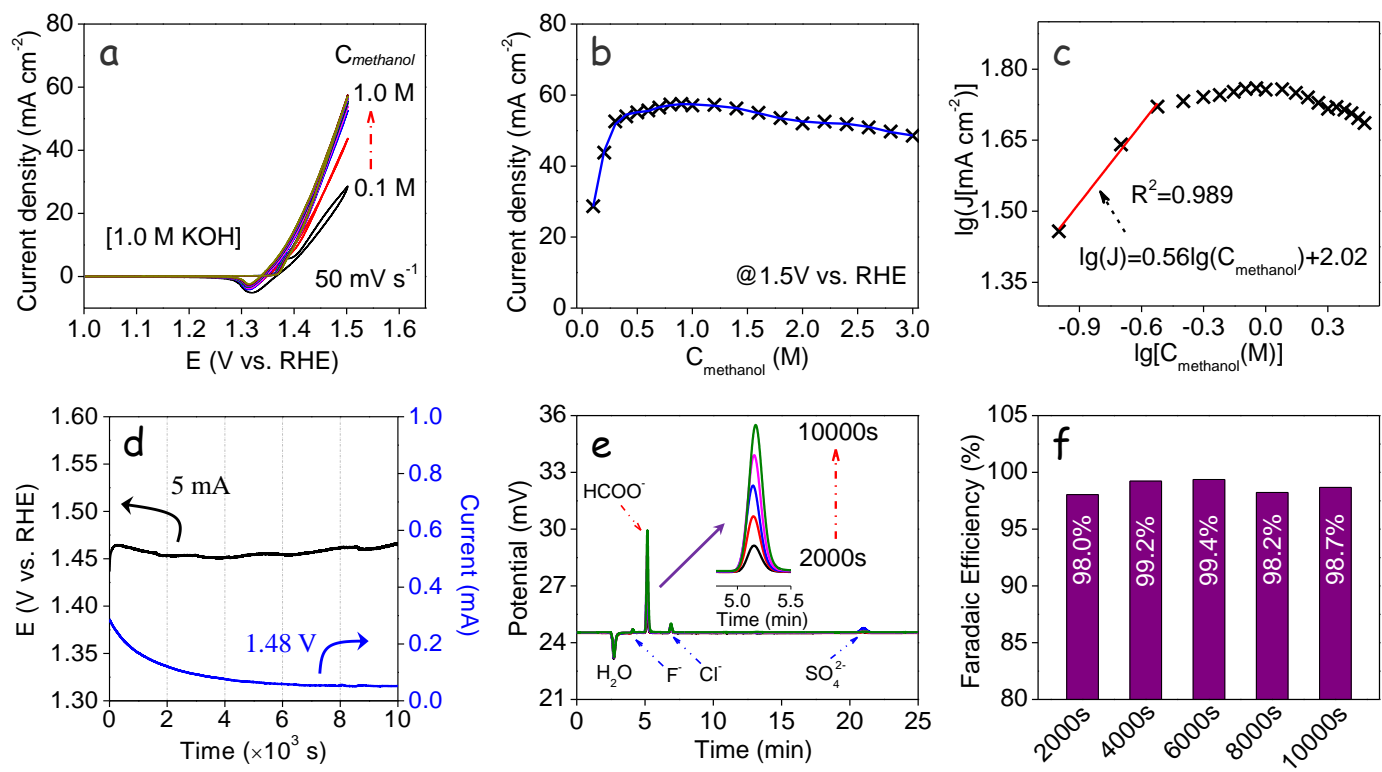

Figure 5. Performance of the $\mathrm{Ni}_{0.75} \mathrm{Fe}_{0.25} \mathrm{Se}_{2}$-based electrode. (a) $\mathrm{CV}$ curves in $1.0 \mathrm{M} \mathrm{KOH}$ electrolyte in the potentials range from $1.0 \mathrm{~V}$ to $1.5 \mathrm{~V}$ at a scan rate of $50 \mathrm{mV} \mathrm{s}^{-1}$ with the 
presence of different methanol concentration from $0.1 \mathrm{M}$ to $1.0 \mathrm{M}$. (b) Current density at 1.5 $\mathrm{V}$ in $1.0 \mathrm{M} \mathrm{KOH}$ containing $0.1 \mathrm{M}$ to $3.0 \mathrm{M}$ methanol. (c) Logarithmic dependence of the current density at $1.50 \mathrm{~V}$ in $1.0 \mathrm{M} \mathrm{KOH}$ solution with the methanol concentration from $0.1 \mathrm{M}$ to $3.0 \mathrm{M}$. (d) $\mathrm{CP}$ profile at a constant current of $5 \mathrm{~mA}$ in $1.0 \mathrm{M} \mathrm{KOH}$ containing $1.0 \mathrm{M}$ methanol and CA response at $1.48 \mathrm{~V}$ during $10,000 \mathrm{~s}$ testing. (e) IC profile in $1.0 \mathrm{M} \mathrm{KOH}$ containing $1.0 \mathrm{M}$ methanol during $10,000 \mathrm{~s}$ CP testing (5 mA) obtained at 2,000 s intervals. (f) Calculated Faradaic efficiency for the methanol-to-formate conversion at 2,000 s, 4,000 s, $6,000 \mathrm{~s}, 8,000 \mathrm{~s}$, and 10,000 s times during CP test.

Figure 5a displays CVs $\left(50 \mathrm{mV} \mathrm{s}^{-1}\right)$ of $\mathrm{Ni}_{0.75} \mathrm{Fe}_{0.25} \mathrm{Se}_{2}$-based electrodes in a $1.0 \mathrm{M} \mathrm{KOH}$ electrolyte containing different methanol concentrations, from $0.1 \mathrm{M}$ to $1.0 \mathrm{M}$. The current density associated to the MOR clearly increased with the methanol concentration, until ca. 0.3 M. Figure $5 \mathrm{~b}$ displays current density vs. methanol concentration at $1.5 \mathrm{~V}$. The current density initially increased with the methanol concentration, from $28.6 \mathrm{~mA} \mathrm{~cm}^{-2}$ at $0.1 \mathrm{M}$, up to 51.8 $\mathrm{mA} \mathrm{cm} \mathrm{cm}^{-2}$ at $0.3 \mathrm{M}$, and it was stabilized at around this value for higher methanol concentrations, up to 3.0 M. A linear fit of the logarithmic dependence of the current density vs. methanol concentration in the low concentration range indicated the methanol reaction order to be ca. 0.6 (Figure 5c).

Averaging the current density obtained from $5 \mathrm{Ni}_{0.75} \mathrm{Fe}_{0.25} \mathrm{Se}_{2}$-based electrodes fabricated from different batches of particles, we calculated a current density of $59.7 \mathrm{~mA} \mathrm{~cm}^{-2}$ at $1.5 \mathrm{~V}$, which decreased to $53.5 \mathrm{~mA} \mathrm{~cm}^{-2}$ after subtracting the current density in $1.0 \mathrm{M} \mathrm{KOH}$ (Figure $\mathrm{S} 11$ ). This value corresponds to $2.2 \mathrm{~A} \mathrm{mg}^{-1}$ (considering the mass of catalyst loaded on the GC), which is the highest MOR activity reported for a Ni-based electrode to date (Table 2).

Table 2. Electrocatalytic performance comparison between the $\mathrm{Ni}_{0.75} \mathrm{Fe}_{0.25} \mathrm{Se}_{2}$ electrodes and other Ni-based electrodes previously reported

\begin{tabular}{ccccc}
\hline \multirow{2}{*}{ Electrocatalyst } & Electrolyte & \multicolumn{2}{c}{ Activities } & \\
& & $(1.5 \mathrm{~V}$ vs RHE $)$ & Reference \\
& $\mathrm{mA} \mathrm{cm}^{-2}$ & $\mathrm{~A} \mathrm{mg}^{-1}$ & \\
\hline $\mathrm{Ni} / \mathrm{rGO}$ & $1.0 \mathrm{M} \mathrm{KOH}+1.0 \mathrm{M}$ methanol & & 1.5 & {$[54]$} \\
$\mathrm{Ni}-\mathrm{CNT} / \mathrm{SiC}$ & $1.0 \mathrm{M} \mathrm{NaOH}+1.0 \mathrm{M}$ methanol & 31.2 & 1.9 & {$[55]$} \\
$(110)$-faceted Ni & $1.0 \mathrm{M} \mathrm{KOH}+1.0 \mathrm{M}$ methanol & 41.1 & 1.4 & {$[49]$} \\
$\mathrm{Ni} /$ beta- zeolite & $0.1 \mathrm{M} \mathrm{NaOH}+0.1 \mathrm{M}$ methanol & 7.5 & 0.2 & {$[56]$} \\
$\mathrm{NiO}$ layer/CNT & $1.0 \mathrm{M} \mathrm{KOH}+0.5 \mathrm{M}$ methanol & 56.7 & & {$[57]$} \\
defect-rich NiO & $1.0 \mathrm{M} \mathrm{KOH}+0.5 \mathrm{M}$ methanol & 24.3 & 0.1 & {$[44]$} \\
$\mathrm{NiO} / \mathrm{Ni}$ heterostructures & $1.0 \mathrm{M} \mathrm{KOH}+2.0 \mathrm{M}$ methanol & 9.4 & 1.8 & {$[58]$} \\
\hline
\end{tabular}




\begin{tabular}{ccccc}
\hline $\mathrm{Ni}_{2} \mathrm{Co}_{2}$ & $1.0 \mathrm{M} \mathrm{NaOH}+0.5 \mathrm{M}$ methanol & 18.5 & & {$[19]$} \\
$\mathrm{Ni}_{2.5} \mathrm{Co}_{0.5} \mathrm{Sn}_{2}$ & $1.0 \mathrm{M} \mathrm{KOH}+1.0 \mathrm{M}$ methanol & 38.6 & 0.6 & {$[47]$} \\
$\mathrm{NiCo} / \mathrm{NiO}-\mathrm{CoO} /$ carbon & $0.5 \mathrm{M} \mathrm{NaOH}+0.5 \mathrm{M}$ methanol & 75.6 & & {$[59]$} \\
$\mathrm{NiMoO}_{4}$ & $1.0 \mathrm{M} \mathrm{KOH}+2.0 \mathrm{M}$ methanol & 11.2 & & {$[60]$} \\
$\mathrm{Ni}_{0.75} \mathrm{Cu}_{0.25}$ & $1.0 \mathrm{M} \mathrm{NaOH}+0.5 \mathrm{M}$ methanol & 23.6 & 0.1 & {$[43]$} \\
$\mathrm{Cu}-\mathrm{Ni} / \mathrm{CNT}$ & $1.0 \mathrm{M} \mathrm{NaOH}+3.0 \mathrm{M}$ methanol & & 0.3 & {$[21]$} \\
$1 \mathrm{D} \mathrm{Cu} / \mathrm{NiCu}$ & $1.0 \mathrm{M} \mathrm{KOH}+1.0 \mathrm{M}$ methanol & 25.1 & 0.6 & {$[61]$} \\
$\mathrm{Fe}-\mathrm{Ni} \mathrm{core} / \mathrm{shell}$ & $1.0 \mathrm{M} \mathrm{NaOH}+1.0 \mathrm{M}$ methanol & 6.5 & 1.4 & {$[27]$} \\
$\mathrm{Ni}_{0.97} \mathrm{Bi}_{0.03}$ & $1.0 \mathrm{M} \mathrm{KOH}+1.0 \mathrm{M}$ methanol & & 0.8 & {$[42]$} \\
$\mathrm{Ni}-\mathrm{B} \mathrm{amorphous} \mathrm{alloy} / \mathrm{Cu}$ & $1.0 \mathrm{M} \mathrm{KOH}+0.3 \mathrm{M}$ methanol & 66.1 & & {$[52]$} \\
$3 \mathrm{D} \mathrm{Ni}-\mathrm{P}-\mathrm{O}$ & $0.5 \mathrm{M} \mathrm{KOH}+1.0 \mathrm{M}$ methanol & & 1.1 & {$[62]$} \\
$\mathrm{Branched} \mathrm{Ni}_{3} \mathrm{C}$ & $1.0 \mathrm{M} \mathrm{KOH}+1.0 \mathrm{M}$ methanol & 51.2 & 1.6 & {$[26]$} \\
$\mathrm{NiSe} / \mathrm{Ni}$ & $1.0 \mathrm{M} \mathrm{KOH}+0.5 \mathrm{M}$ methanol & 132 & & {$[28]$} \\
$\mathrm{Ni}_{0.75} \mathrm{Fe}_{0.25} \mathrm{Se}_{2}$ & $1.0 \mathrm{M} \mathrm{KOH}+1.0 \mathrm{M}$ methanol & 53.5 & 2.2 & This work \\
\hline
\end{tabular}

Figure $5 \mathrm{~d}$ displays results from $\mathrm{CP}$ test at $5 \mathrm{~mA}$ in a $1.0 \mathrm{M} \mathrm{KOH}$ electrolyte containing $1.0 \mathrm{M}$ methanol. A relatively stable potential, in the range $1.45-1.47 \mathrm{~V}$, was required to maintain a stable current during the $10,000 \mathrm{~s}$ test. Figure $5 \mathrm{~d}$ displays the low current obtained during a $\mathrm{CA}$ test at $1.48 \mathrm{~V}$ in $1.0 \mathrm{M} \mathrm{KOH}$ without methanol, demonstrating the current measured during $\mathrm{CP}$ to be directly related to the methanol oxidation.

The reaction products were quantified by analyzing the ion type and concentration during CP test by means of IC (Figure 5d). As shown in Figure 5e, several peaks were identified at 2.7, 4.1, 5.2, 6.9, and $21 \mathrm{~min}$, which were ascribed to water, $\mathrm{F}^{-}, \mathrm{HCOO}^{-}, \mathrm{Cl}^{-}$, and $\mathrm{SO}_{4}{ }^{2-}$ respectively. Notice how the largest peak corresponded to formate, which generation involved 4 electrons in the overall reaction in alkaline media:[6]

$\mathrm{CH}_{3} \mathrm{OH}+5 \mathrm{OH}^{-} \rightarrow \mathrm{HCOO}^{-}+\mathrm{H}_{2} \mathrm{O}+4 e^{-}$

As displayed in the inset in figure $5 \mathrm{e}$, the formate concentration increased with the $\mathrm{CP}$ time, i.e. with the total amount of charge flown (Table S1). From these values, the Faradaic efficiency of the methanol-to-formate conversion was calculated to be close to $99 \%$ (Figure 5f). In theseconditions, the production rate of formate was $0.23 \mathrm{mmol} \mathrm{cm}^{-2} \mathrm{~h}^{-1}$.

The stability of $\mathrm{Ni}_{0.75} \mathrm{Fe}_{0.25} \mathrm{Se}_{2}$ electrodes was further investigated by means of $\mathrm{CP}, \mathrm{CA}$ and continuous $\mathrm{CVs}$ in $1.0 \mathrm{M} \mathrm{KOH}$ electrolyte with $1.0 \mathrm{M}$ methanol. Figure 6a displays a $\mathrm{CP}$ 
profile at $50 \mathrm{~mA} \mathrm{~cm}^{-2}$. The initial voltage was $1.46 \mathrm{~V}$, and after $50,000 \mathrm{~s} \mathrm{CP}$ test this value increased by just ca. $50 \mathrm{mV}$. After this test, $1.27 \mathrm{mmol}$ formate had been electrochemically produced through the injection of $500 \mathrm{C}$ of charge, which corresponded to a Faradaic efficiency of $98.2 \%$ and a production rate of $0.47 \mathrm{mmol} \mathrm{cm}^{-2} \mathrm{~h}^{-1}$.

CA analysis at $1.50 \mathrm{~V}$ displayed the current density of the $\mathrm{Ni}_{0.75} \mathrm{Fe}_{0.25} \mathrm{Se}_{2}$ electrode to gradually decrease. While a $27.4 \%$ lower current density was obtained after $50,000 \mathrm{~s}$, the retained current density $\left(38.9 \mathrm{~mA} \mathrm{~cm}^{-2}\right)$ was still well above the initial current densities of most Ni-based MOR catalysts previously reported (Table 2). As shown in the inset of Figure $6 \mathrm{~b}$, after the long-term electrocatalytic process $(50,000 \mathrm{~s} \mathrm{CA})$ in alkaline media and at high potential, the catalyst particle size and morphology remained constant.[63-65]

$\mathrm{CV}$ profiles showed a gradual current density decay in the potential window $1.0-1.5 \mathrm{~V}$ upon long term cycling (figure $6 \mathrm{c}$ ). The current density at $1.5 \mathrm{~V}$ retained $91.9 \%, 83.9 \%, 74.0 \%$, $67.7 \%$, and $61.5 \%$ of the initial value after $200,400,600,800$, and 1000 cycles, respectively (Figure 6d).
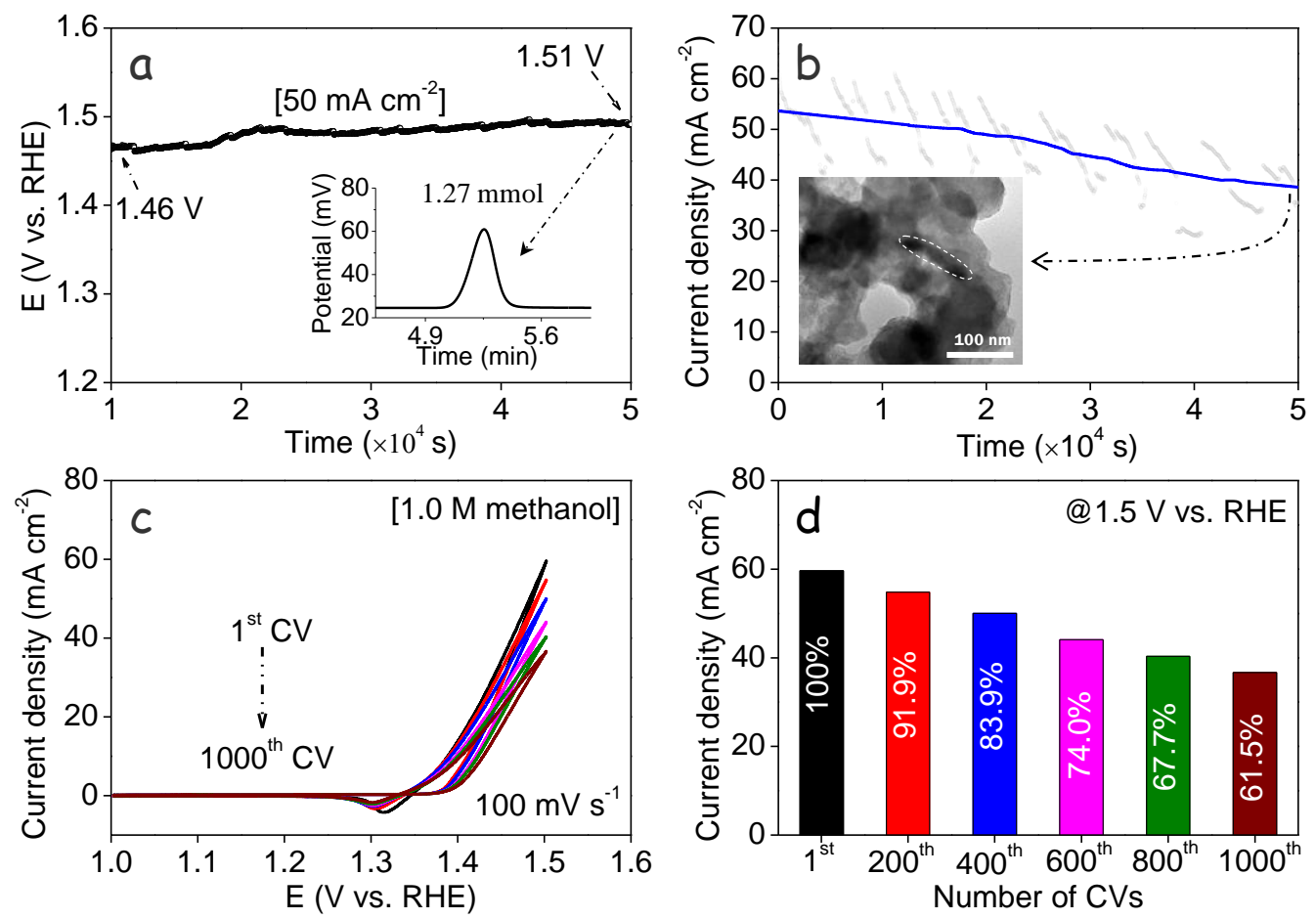

Figure 6. Stability test of the $\mathrm{Ni}_{0.75} \mathrm{Fe}_{0.25} \mathrm{Se}_{2}$-based electrode in $1.0 \mathrm{M} \mathrm{KOH}$ with $1.0 \mathrm{M}$ methanol. (a) CP profile during 50,000 s operation at a constant current density of $50 \mathrm{~mA} \mathrm{~cm}^{-2}$ The IC profile obtained from the solution after completing the CP test is also plotted as inset. 
(b) CA response at $1.5 \mathrm{~V}$ during 50,000 s test. The inset shows the morphology of the catalyst after the test. (c) Continuous 1,000 CVs cycling in the potential range of 1.0-1.5 V. (d) The corresponding current density change at the $200^{\text {th }}, 400^{\text {th }}, 600^{\text {th }}, 800^{\text {th }}$, and $1000^{\text {th }} \mathrm{CV}$ compared with the initial $\mathrm{CV}$ at $1.5 \mathrm{~V}$.

\section{Conclusion}

In summary, we reported a fast solution-based route to produce nickel iron diselenide nanorods. The materials were thoroughly characterized and their performance toward MOR was tested. We found the incorporation of iron into the $\mathrm{NiSe}_{2}$ structure to modify the material electronic structure and to significantly improve the electrocatalytic performance, including ECSA, surface coverage of active species for MOR, and diffusivity of limiting species in alkaline media. The optimal composition was found to be $\mathrm{Ni}_{0.75} \mathrm{Fe}_{0.25} \mathrm{Se}_{2}$. Electrodes based on $\mathrm{Ni}_{0.75} \mathrm{Fe}_{0.25} \mathrm{Se}_{2}$ nanorods delivered a current density up to $53.5 \mathrm{~mA} \mathrm{~cm}{ }^{-2}$, corresponding to 2.2 $\mathrm{A} \mathrm{mg}^{-1}$, in $1.0 \mathrm{M} \mathrm{KOH}$ electrolyte containing $1.0 \mathrm{M}$ methanol at $1.5 \mathrm{~V}$. These electrodes were able to produce $0.47 \mathrm{mmol} \mathrm{cm}^{-2} \mathrm{~h}^{-1}$ of formate at $50 \mathrm{~mA} \mathrm{~cm}$ with a Faradaic conversion efficiency of $99 \%$ and to continuously work for over 50,000 s with a low efficiency loss. Taking into account the economic advantages of using a noble-metal-free catalyst, its high Faradaic efficiency, and ambient operation, the electrochemical conversion of methanol to formate might indeed become an efficient approach to add value to biomass-derived chemicals.

\section{Author Information}

Corresponding Author

* Prof. Andreu Cabot: acabot@irec.cat

* Prof. Chunhua Cui: chunhua.cui@uestc.edu.cn

\section{Author contributions}

The manuscript was contributed and authorized by all authors. C. Cui and A. Cabot conceived and guided the project, and supervised the work. J. Li designed the experiments, performed electrochemical measurements, and wrote the first draft. C. Xing and Y. Zhang produced the NRs, conducted XRD. M. C. Spadaro, T. Zhang, and J. Arbiol conducted structural and 
compositional NRs characterization by means of HRTEM and EELS, and discussed the results. Q. Wu and Y. Yu provided assistance to the EPR and IC measurement, respectively. S. He significantly joined the results discussion. J. Llorca measured and discussed XPS data. This manuscript was corrected and improved by all authors.

\section{Acknowledgements}

J. Li obtained International Postdoctoral Exchange Fellowship Program (Talent-Introduction program) in 2019 and is grateful for the project (2019M663468) funded by the China Postdoctoral Science Foundation. This work was supported from the UESTC start-up funding and the Recruitment Program of Thousand Youth Talents. It was also supported by the European Regional Development Funds and by the Spanish Ministerio de Economía y Competitividad through the project SEHTOP (ENE2016-77798-C4-3-R) and VALPEC (ENE2017-85087-C3). C. Xing, Y. Zhang, T. Zhang, and X. Wang are grateful for the China Scholarship Council (CSC) for scholarship support. M. C. Spadaro, T. Zhang, and J. Arbiol acknowledge funding from Generalitat de Catalunya 2017 SGR 327. ICN2 acknowledges support from the Severo Ochoa Programme (MINECO, Grant no. SEV-2013-0295). IREC and ICN2 are funded by the CERCA Programme / Generalitat de Catalunya. Part of the present work has been performed in the framework of Universitat Autònoma de Barcelona Materials Science PhD program. J. Llorca is a Serra Húnter Fellow and is grateful to MICINN/FEDER RTI2018-093996-B-C31, GC 2017 SGR 128 and to ICREA Academia program.

\section{Conflict of interest}

The authors declare no competing financial interest.

\section{Reference}

[1] Y. Gogotsi, P. Simon, True performance metrics in electrochemical energy storage, Science (80-. ). 334 (2011) 917-918. doi:10.1126/science.1213003.

[2] N.M. Markovic, Electrocatalysis: Interfacing electrochemistry, Nat. Mater. 12 (2013) 101-102. doi:10.1038/nmat3554.

[3] D.A. Bulushev, J.R.H. Ross, Towards Sustainable Production of Formic Acid, 
ChemSusChem. 11 (2018) 821-836. doi:10.1002/cssc.201702075.

[4] N. Kakati, J. Maiti, S.H. Lee, S.H. Jee, B. Viswanathan, Y.S. Yoon, Anode catalysts for direct methanol fuel cells in acidic media: Do we have any alternative for Pt or Pt-Ru?, Chem. Rev. 114 (2014) 12397-12429. doi:10.1021/cr400389f.

[5] Q. Liu, L. Wu, S. Gülak, N. Rockstroh, R. Jackstell, M. Beller, Towards a sustainable synthesis of formate salts: Combined catalytic methanol dehydrogenation and bicarbonate hydrogenation, Angew. Chemie - Int. Ed. 53 (2014) 7085-7088. doi:10.1002/anie.201400456.

[6] M. Li, X. Deng, K. Xiang, Y. Liang, B. Zhao, J. Hao, J.L. Luo, X.Z. Fu, Value-Added Formate Production from Selective Methanol Oxidation as Anodic Reaction to Enhance Electrochemical Hydrogen Cogeneration, ChemSusChem. 13 (2019) 914921. doi:10.1002/cssc.201902921.

[7] J. Eppinger, K.W. Huang, Formic Acid as a Hydrogen Energy Carrier, ACS Energy Lett. 2 (2017) 188-195. doi:10.1021/acsenergylett.6b00574.

[8] M.G. Mura, L. De Luca, G. Giacomelli, A. Porcheddu, Formic acid: A promising bio-renewable feedstock for fine chemicals, Adv. Synth. Catal. 354 (2012) 3180-3186. doi:10.1002/adsc.201200748.

[9] F. Valentini, V. Kozell, C. Petrucci, A. Marrocchi, Y. Gu, D. Gelman, L. Vaccaro, Formic acid, a biomass-derived source of energy and hydrogen for biomass upgrading, Energy Environ. Sci. 12 (2019) 2646-2664. doi:10.1039/c9ee01747j.

[10] D.R. Palo, R.A. Dagle, J.D. Holladay, Methanol steam reforming for hydrogen production, Chem. Rev. 107 (2007) 3992-4021. doi:10.1021/cr050198b.

[11] M. Li, X. Deng, K. Xiang, Y. Liang, B. Zhao, J. Hao, J.L. Luo, X.Z. Fu, Value-Added Formate Production from Selective Methanol Oxidation as Anodic Reaction to Enhance Electrochemical Hydrogen Cogeneration, ChemSusChem. 13 (2020) 914921. doi:10.1002/cssc.201902921.

[12] X. Chen, Y. Liu, J. Wu, Sustainable production of formic acid from biomass and carbon dioxide, Mol. Catal. 483 (2020) 110716. doi:10.1016/j.mcat.2019.110716.

[13] S. Moret, P.J. Dyson, G. Laurenczy, Direct synthesis of formic acid from carbon dioxide by hydrogenation in acidic media, Nat. Commun. 5 (2014) 1-7. doi:10.1038/ncomms5017.

[14] F. Joó, Breakthroughs in hydrogen storagel-formic acid as a sustainable storage material for hydrogen, ChemSusChem. 1 (2008) 805-808. doi:10.1002/cssc.200800133.

[15] L. Du, Y. Shao, J. Sun, G. Yin, C. Du, Y. Wang, Electrocatalytic valorisation of biomass derived chemicals, Catal. Sci. Technol. 8 (2018) 3216-3232. doi:10.1039/c8cy00533h.

[16] M.H. Oh, T. Yu, S.H. Yu, B. Lim, K.T. Ko, M.G. Willinger, D.H. Seo, B.H. Kim, M.G. Cho, J.H. Park, K. Kang, Y.E. Sung, N. Pinna, T. Hyeon, Galvanic replacement reactions in metal oxide nanocrystals, Science (80-. ). 340 (2013) 964-968. doi:10.1126/science.1234751.

[17] Y. Tong, X. Yan, J. Liang, S.X. Dou, Metal-Based Electrocatalysts for Methanol Electro-Oxidation: Progress, Opportunities, and Challenges, Small. (2019) 1904126. doi:10.1002/smll.201904126. 
[18] M.A. Abdelkareem, E.T. Sayed, H.O. Mohamed, M. Obaid, H. Rezk, K.J. Chae, Nonprecious anodic catalysts for low-molecular-hydrocarbon fuel cells: Theoretical consideration and current progress, Prog. Energy Combust. Sci. 77 (2020) 100805. doi:10.1016/j.pecs.2019.100805.

[19] X. Cui, W. Guo, M. Zhou, Y. Yang, Y. Li, P. Xiao, Y. Zhang, X. Zhang, Promoting effect of $\mathrm{Co}$ in $\mathrm{Ni} \mathrm{m}$ Con $(\mathrm{m}+\mathrm{n}=4)$ bimetallic electrocatalysts for methanol oxidation reaction, ACS Appl. Mater. Interfaces. 7 (2015) 493-503. doi:10.1021/am506554b.

[20] M. Zhao, K. Abe, S.I. Yamaura, Y. Yamamoto, N. Asao, Fabrication of Pd-Ni-P metallic glass nanoparticles and their application as highly durable catalysts in methanol electro-oxidation, Chem. Mater. 26 (2014) 1056-1061. doi:10.1021/cm403185h.

[21] I.S. Pieta, A. Rathi, P. Pieta, R. Nowakowski, M. Hołdynski, M. Pisarek, A. Kaminska, M.B. Gawande, R. Zboril, Electrocatalytic methanol oxidation over $\mathrm{Cu}, \mathrm{Ni}$ and bimetallic $\mathrm{Cu}-\mathrm{Ni}$ nanoparticles supported on graphitic carbon nitride, Appl. Catal. B Environ. 244 (2019) 272-283. doi:10.1016/j.apcatb.2018.10.072.

[22] B. Wang, Y. Cao, Y. Chen, R. Wang, X. Wang, X. Lai, C. Xiao, J. Tu, S. Ding, Microwave-assisted fast synthesis of hierarchical NiCo2O4 nanoflower-like supported $\mathrm{Ni}(\mathrm{OH}) 2$ nanoparticles with an enhanced electrocatalytic activity towards methanol oxidation, Inorg. Chem. Front. 5 (2018) 172-182. doi:10.1039/c7qi00583k.

[23] L. Gu, L. Qian, Y. Lei, Y. Wang, J. Li, H. Yuan, D. Xiao, Microwave-assisted synthesis of nanosphere-like NiCo2O 4 consisting of porous nanosheets and its application in electro-catalytic oxidation of methanol, J. Power Sources. 261 (2014) 317-323. doi:10.1016/j.jpowsour.2014.03.098.

[24] C. Liu, W. Zhou, J. Zhang, Z. Chen, S. Liu, Y. Zhang, J. Yang, L. Xu, W. Hu, Y. Chen, Y. Deng, Air-Assisted Transient Synthesis of Metastable Nickel Oxide Boosting Alkaline Fuel Oxidation Reaction, Adv. Energy Mater. (2020) 2001397. doi:10.1002/aenm.202001397.

[25] W. Yang, X. Yang, J. Jia, C. Hou, H. Gao, Y. Mao, C. Wang, J. Lin, X. Luo, Oxygen vacancies confined in ultrathin nickel oxide nanosheets for enhanced electrocatalytic methanol oxidation, Appl. Catal. B Environ. 244 (2019) 1096-1102. doi:10.1016/j.apcatb.2018.12.038.

[26] J. Li, R. Wei, X. Wang, Y. Zuo, X. Han, J. Arbiol, J. Llorca, Y. Yang, A. Cabot, C. Cui, Selective Methanol-to-Formate Electrocatalytic Conversion on Branched Nickel Carbide, Angew. Chemie. (2020) ange.202004301. doi:10.1002/ange.202004301.

[27] S.L. Candelaria, N.M. Bedford, T.J. Woehl, N.S. Rentz, A.R. Showalter, S. Pylypenko, B.A. Bunker, S. Lee, B. Reinhart, Y. Ren, S.P. Ertem, E.B. Coughlin, N.A. Sather, J.L. Horan, A.M. Herring, L.F. Greenlee, Multi-Component Fe-Ni Hydroxide Nanocatalyst for Oxygen Evolution and Methanol Oxidation Reactions under Alkaline Conditions, ACS Catal. 7 (2017) 365-379. doi:10.1021/acscatal.6b02552.

[28] Q. Luo, M. Peng, X. Sun, A.M. Asiri, In situ growth of nickel selenide nanowire arrays on nickel foil for methanol electro-oxidation in alkaline media, RSC Adv. 5 (2015) 87051-87054. doi:10.1039/c5ra12275a.

[29] J.F. Moulder, W.F. Stickle, P.E. Sobol, K.D. Bomben, Handbook of X-ray 
photoelectron spectroscopy: a reference book of standard spectra for identification and interpretation of XPS data, Perkin-Elmer Corp., Minnesota, 1992. https://www.cnyn.unam.mx/ wencel/XPS/MANXPS.pdf.

[30] J. Li, X. Xu, X. Yu, X. Han, T. Zhang, Y. Zuo, C. Zhang, D. Yang, X. Wang, Z. Luo, J. Arbiol, J. Llorca, J. Liu, A. Cabot, Monodisperse CoSn and NiSn Nanoparticles Supported on Commercial Carbon as Anode for Lithium- And Potassium-Ion Batteries, ACS Appl. Mater. Interfaces. 12 (2020) 4414-4422. doi:10.1021/acsami.9b16418.

[31] J. Li, X. Xu, Z. Luo, C. Zhang, Y. Zuo, T. Zhang, P. Tang, M.F. Infante-Carrió, J. Arbiol, J. Llorca, J. Liu, A. Cabot, Co-Sn Nanocrystalline Solid Solutions as Anode Materials in Lithium-Ion Batteries with High Pseudocapacitive Contribution, ChemSusChem. 12 (2019) 1451-1458. doi:10.1002/cssc.201802662.

[32] J.F. Moulder, W.F. Stickle, P.E. Sobol, K.D. Bomben, Handbook of X-ray photoelectron spectroscopy: a reference book of standard spectra for identification and $\begin{array}{llll}\text { interpretation } & \text { of } & \text { XPS }\end{array}$ https://www.cnyn.unam.mx/ wencel/XPS/MANXPS.pdf.

[33] Y. Du, G. Cheng, W. Luo, Colloidal synthesis of urchin-like Fe doped NiSe2 for efficient oxygen evolution, Nanoscale. 9 (2017) 6821-6825. doi:10.1039/c7nr01413a.

[34] J. Zhou, L. Yuan, J. Wang, L. Song, Y. You, R. Zhou, J. Zhang, J. Xu, Combinational modulations of NiSe2 nanodendrites by phase engineering and iron-doping towards an efficient oxygen evolution reaction, J. Mater. Chem. A. 8 (2020) 8113-8120. doi:10.1039/d0ta00860e.

[35] X. Xu, F. Song, X. Hu, A nickel iron diselenide-derived efficient oxygen-evolution catalyst, Nat. Commun. 7 (2016) 1-7. doi:10.1038/ncomms12324.

[36] B. Orayech, L. Ortega-San-Martín, I. Urcelay-Olabarria, L. Lezama, T. Rojo, M.I. Arriortua, J.M. Igartua, The effect of partial substitution of Ni by Mg on the structural, magnetic and spectroscopic properties of the double perovskite Sr2NiTeO6, Dalt. Trans. 45 (2016) 14378-14393. doi:10.1039/c6dt02473d.

[37] A. Solano-Peralta, J.P. Saucedo-Vázquez, R. Escudero, H. Höpfl, H. El-Mkami, G.M. Smith, M.E. Sosa-Torres, Magnetic and high-frequency EPR studies of an octahedral Fe(iii) compound with unusual zero-field splitting parameters, Dalt. Trans. 0 (2009) 1668-1674. doi:10.1039/b814225d.

[38] K. Zhu, T. Wu, M. Li, R. Lu, X. Zhu, W. Yang, Perovskites decorated with oxygen vacancies and $\mathrm{Fe}-\mathrm{Ni}$ alloy nanoparticles as high-efficiency electrocatalysts for the oxygen evolution reaction, J. Mater. Chem. A. 5 (2017) 19836-19845. doi:10.1039/c7ta05404a.

[39] D.M. MacArthur, The Hydrated Nickel Hydroxide Electrode Potential Sweep Experiments, The Electrochemical Society, 1970. doi:10.1149/1.2407535.

[40] C.C.L. McCrory, S. Jung, I.M. Ferrer, S.M. Chatman, J.C. Peters, T.F. Jaramillo, Benchmarking Hydrogen Evolving Reaction and Oxygen Evolving Reaction Electrocatalysts for Solar Water Splitting Devices, J. Am. Chem. Soc. 137 (2015) 4347-4357. doi:10.1021/ja510442p.

[41] C.C.L. McCrory, S. Jung, J.C. Peters, T.F. Jaramillo, Benchmarking Heterogeneous Electrocatalysts for the Oxygen Evolution Reaction, J. Am. Chem. Soc. 135 (2013) 16977-16987. doi:10.1021/ja407115p. 
[42] A.A. Dubale, Y. Zheng, H. Wang, R. Hübner, Y. Li, J. Yang, J. Zhang, N.K. Sethi, L. He, Z. Zheng, W. Liu, High-Performance Bismuth-Doped Nickel Aerogel Electrocatalyst for the Methanol Oxidation Reaction, Angew. Chemie - Int. Ed. 59 (2020) 13891-13899. doi:10.1002/anie.202004314.

[43] X. Cui, P. Xiao, J. Wang, M. Zhou, W. Guo, Y. Yang, Y. He, Z. Wang, Y. Yang, Y. Zhang, Z. Lin, Highly Branched Metal Alloy Networks with Superior Activities for the Methanol Oxidation Reaction, Angew. Chemie - Int. Ed. 56 (2017) 4488-4493. doi:10.1002/anie.201701149.

[44] T.J. Wang, H. Huang, X.R. Wu, H.C. Yao, F.M. Li, P. Chen, P.J. Jin, Z.W. Deng, Y. Chen, Selflate synthesis of defect-rich $\mathrm{NiO}$ nanotubes as efficient electrocatalysts for methanol oxidation reaction, Nanoscale. 11 (2019) 19783-19790. doi:10.1039/c9nr06304h.

[45] D. Chen, S.D. Minteer, Mechanistic study of nickel based catalysts for oxygen evolution and methanol oxidation in alkaline medium, J. Power Sources. 284 (2015) 27-37. doi:10.1016/j.jpowsour.2015.02.143.

[46] M.W. Khalil, M.A. Abdel Rahim, A. Zimmer, H.B. Hassan, R.M. Abdel Hameed, Nickel impregnated silicalite-1 as an electro-catalyst for methanol oxidation, J. Power Sources. 144 (2005) 35-41. doi:10.1016/j.jpowsour.2004.12.014.

[47] J. Li, Z. Luo, F. He, Y. Zuo, C. Zhang, J. Liu, R. Du, X. Yu, T. Zhang, P. Tang, M.F.I. Carrió, J. Arbiol, J. Llorca, A. Cabot, Colloidal Ni-Co-Sn Nanoparticles as Efficient Electrocatalysts for the Methanol Oxidation Reaction, J. Mater. Chem. A. 6 (2018) 22915-22924. doi:10.1039/C8TA08242A.

[48] R.M. Abdel Hameed, R.M. El-Sherif, Microwave irradiated nickel nanoparticles on Vulcan XC-72R carbon black for methanol oxidation reaction in $\mathrm{KOH}$ solution, Appl. Catal. B Environ. 162 (2015) 217-226. doi:10.1016/j.apcatb.2014.06.057.

[49] J. Li, Y. Zuo, J. Liu, X. Wang, X. Yu, R. Du, T. Zhang, M.F. Infante-Carrió, P. Tang, J. Arbiol, J. Llorca, Z. Luo, A. Cabot, Superior methanol electrooxidation performance of (110)-faceted nickel polyhedral nanocrystals, J. Mater. Chem. A. 7 (2019) 2203622043. doi:10.1039/c9ta07066d.

[50] A.J. Bard, L.R. Faulkner, N. York, C. @bullet, W. Brisbane, S.E. Toronto, Electrochemical methods: fundamentals and applications, 2nd editio, John Wiley \& Sons, Inc., New York, Chichester, Weinheim, Brisbane, Singapore, Toronto, 2001.

[51] L. Xiao, J.T. Lu, P.F. Liu, L. Zhuang, J. Yan, Y. Hu, B. Mao, C. Lin, Proton diffusion determination and dual structure model for nickel hydroxide based on potential step measurements on single spherical beads, J. Phys. Chem. B. 109 (2005) 3860-3867. doi:10.1021/jp045888i.

[52] S.J. Zhang, Y.X. Zheng, L.S. Yuan, L.H. Zhao, Ni-B amorphous alloy nanoparticles modified nanoporous $\mathrm{Cu}$ toward ethanol oxidation in alkaline medium, J. Power Sources. 247 (2014) 428-436. doi:10.1016/j.jpowsour.2013.08.129.

[53] L.S. Yuan, Y.X. Zheng, M.L. Jia, S.J. Zhang, X.L. Wang, C. Peng, Nanoporous nickel-copper-phosphorus amorphous alloy film for methanol electro-oxidation in alkaline medium, Electrochim. Acta. 154 (2015) 54-62. doi:10.1016/j.electacta.2014.12.055.

[54] H. Sun, Y. Ye, J. Liu, Z. Tian, Y. Cai, P. Li, C. Liang, Pure Ni nanocrystallines 
anchored on rGO present ultrahigh electrocatalytic activity and stability in methanol oxidation, Chem. Commun. 54 (2018) 1563-1566. doi:10.1039/c7cc09361f.

[55] S. Xie, X.-L. Tong, G.-Q. Jin, Y. Qin, X.-Y. Guo, CNT-Ni/SiC hierarchical nanostructures: preparation and their application in electrocatalytic oxidation of methanol, J. Mater. Chem. A. 1 (2013) 2104-2109. doi:10.1039/C2TA01002J.

[56] Y. Liao, S. Pan, C. Bian, X. Meng, F.S. Xiao, Improved catalytic activity in methanol electro-oxidation over the nickel form of aluminum-rich beta-SDS zeolite modified electrode, J. Mater. Chem. A. 3 (2015) 5811-5814. doi:10.1039/c4ta06699e.

[57] X. Tong, Y. Qin, X. Guo, O. Moutanabbir, X. Ao, E. Pippel, L. Zhang, M. Knez, Enhanced catalytic activity for methanol electro-oxidation of uniformly dispersed nickel oxide nanoparticles-carbon nanotube hybrid materials, Small. 8 (2012) 33903395. doi:10.1002/smll.201200839.

[58] J. Wang, D. Teschner, Y. Yao, X. Huang, M. Willinger, L. Shao, R. Schlögl, Fabrication of nanoscale $\mathrm{NiO} / \mathrm{Ni}$ heterostructures as electrocatalysts for efficient methanol oxidation, J. Mater. Chem. A. 5 (2017) 9946-9951. doi:10.1039/c7ta01982c.

[59] S. Rezaee, S. Shahrokhian, Facile synthesis of petal-like NiCo/NiO-CoO/nanoporous carbon composite based on mixed-metallic MOFs and their application for electrocatalytic oxidation of methanol, Appl. Catal. B Environ. (2019) 802-813. doi:10.1016/j.apcatb.2018.12.013.

[60] P.R. Jothi, S. Kannan, G. Velayutham, Enhanced methanol electro-oxidation over in-situ carbon and graphene supported one dimensional NiMoO4 nanorods, J. Power Sources. 277 (2015) 350-359. doi:10.1016/j.jpowsour.2014.11.137.

[61] D. Wu, W. Zhang, D. Cheng, Facile Synthesis of $\mathrm{Cu} / \mathrm{NiCu}$ Electrocatalysts Integrating Alloy, Core-Shell, and One-Dimensional Structures for Efficient Methanol Oxidation Reaction, ACS Appl. Mater. Interfaces. 9 (2017) 19843-19851. doi:10.1021/acsami.7b03876.

[62] Y.Y. Tong, C.D. Gu, J.L. Zhang, M.L. Huang, H. Tang, X.L. Wang, J.P. Tu, Three-dimensional astrocyte-network Ni-P-O compound with superior electrocatalytic activity and stability for methanol oxidation in alkaline environments, J. Mater. Chem. A. 3 (2015) 4669-4678. doi:10.1039/c4ta06697a.

[63] Y. Zuo, Y. Liu, J. Li, R. Du, X. Han, T. Zhang, J. Arbiol, N.J. Divins, J. Llorca, N. Guijarro, K. Sivula, A. Cabot, In Situ Electrochemical Oxidation of $\mathrm{Cu} 2 \mathrm{~S}$ into $\mathrm{CuO}$ Nanowires as a Durable and Efficient Electrocatalyst for Oxygen Evolution Reaction , Chem. Mater. 31 (2019) 7732-7743. doi:10.1021/acs.chemmater.9b02790.

[64] X. Yu, Z. Luo, T. Zhang, P. Tang, J. Li, X. Wang, J. Llorca, J. Arbiol, J. Liu, A. Cabot, Stability of $\mathrm{Pd} 3 \mathrm{~Pb}$ Nanocubes during Electrocatalytic Ethanol Oxidation, Chem. Mater. 32 (2020) 2044-2052. doi:10.1021/acs.chemmater.9b05094.

[65] C. Cui, L. Gan, M. Heggen, S. Rudi, P. Strasser, Compositional segregation in shaped Pt alloy nanoparticles and their structural behaviour during electrocatalysis, Nat. Mater. 12 (2013) 765-771. doi:10.1038/nmat3668. 